\title{
Adolescência e Sexualidade: Um Estudo Exploratório em uma Escola de Porto Velho - Ro
}

\author{
Adolescence And Sexuality: An Exploratory \\ Study In A School Of Porto Velho - Ro \\ Adolescencia Y Sexualidad: Un Estudio \\ Exploratorio En Una Escuela De Porto Velho - Ro
}

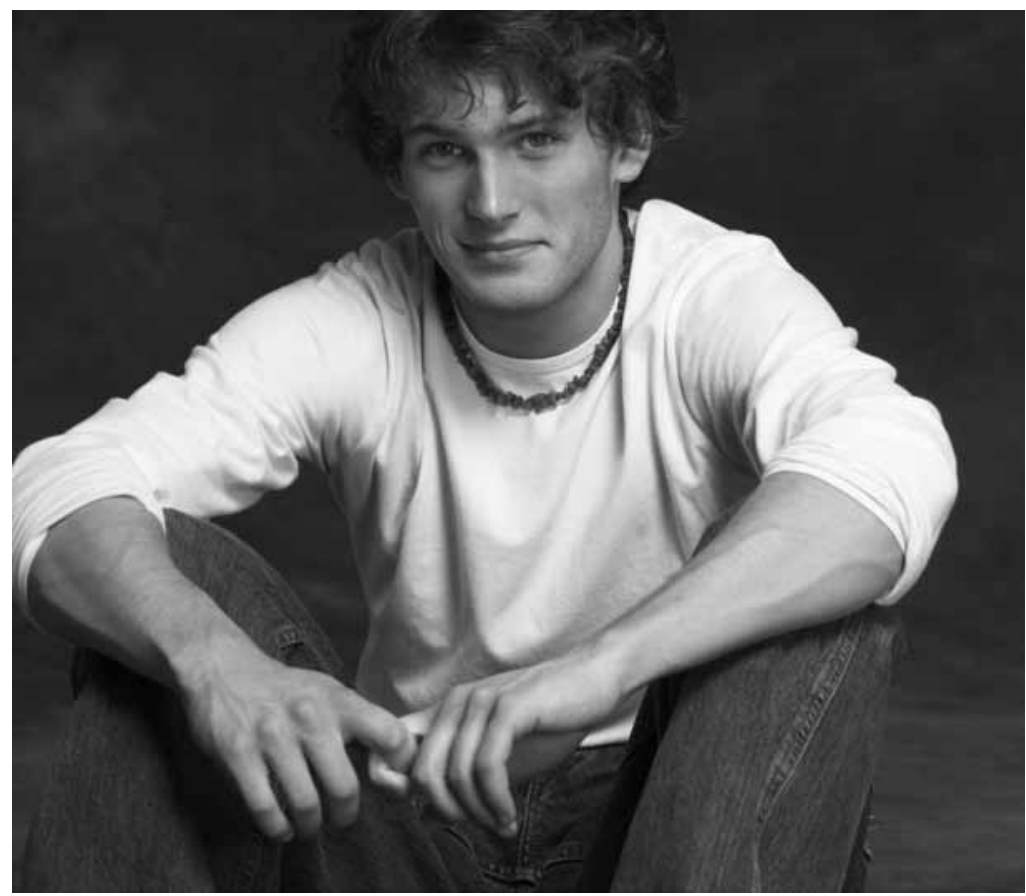


Resumo: Esta pesquisa teve como objetivo investigar a concepção que os adolescentes possuem a respeito do próprio comportamento sexual assim como verificar como buscam orientação sobre esse assunto, qual a avaliação que fazem dos seus primeiros contatos sensuais e o que pensam das experiências relatadas pelos amigos. Para tanto, foram pesquisados jovens de ambos os gêneros, de 12 a 17 anos, alunos do 7우 ano do ensino fundamental ao $2^{\underline{O}}$ ano do ensino médio de uma escola pública localizada na periferia do Município de Porto Velho (RO). Realizou-se estudo exploratório, de natureza descritiva, com o uso de metodologia quanti-qualitativa, utilizando-se um questionário com perguntas abertas e fechadas como instrumento. Verificou-se que os adolescentes, mesmo conhecendo os métodos anticoncepcionais e de prevenção às doenças sexualmente transmissíveis, iniciam a vida sexual expondo-se a riscos. Contudo, acreditam que se protegem dos riscos inerentes ao ato sexual, mas, por outro lado, afirmam que os amigos não se comportam de tal forma.

Palavras-chave: Adolescência. Sexualidade. Vulnerabilidade. Saúde pública.

Abstract: This research aimed to investigate the conception that teenagers have about their own sexual behavior, as well as verify which evaluation they make about their first sensual contacts and what they think of the experiences reported by friends. In order to reach the results, we contacted male and female students from 7th grade students in elementary school to 2 nd grade of high school in a public school in the suburbs of an urban area of Porto Velho - RO. A descriptive nature exploratory study was made, with the concept of quantitative and qualitative methodology, using both open and closed questionaire answers as a tool. It was found that teenagers, even knowing contraceptive methods and prevention of sexually transmitted diseases, start their sexual lives exposing themselves to risks. However, they believe that they are protected from the risks of insecure sex, but, on the other hand, they say their friends do not behave the same way. Keywords: Adolescent. Sexuality. Vulnerability. Public health.

Resumen : Esta investigación ha tenido como objetivo investigar la concepción que los adolescentes poseen en cuanto al propio comportamiento sexual, así como verificar cómo ellos buscan orientación acerca de ese asunto, qué evaluación realizan de sus primeros contactos sensuales y qué piensan de las experiencias relatadas por los amigos. Para tanto, han sido investigados jóvenes de ambos géneros, de 12 a 17 años de edad, alumnos desde el $7^{0}$ grado de la enseñanza primaria hasta el $2^{\circ}$ grado de la enseñanza secundaria de una escuela pública ubicada en la periferia del municipio de Porto Velho - RO. Se ha llevado a cabo un estudio exploratorio, de naturaleza descriptiva, con el uso de metodología cuantitativo-cualitativa, utilizándose un cuestionario con preguntas abiertas y cerradas como instrumento. Se ha verificado que los adolescentes, aún conociendo los métodos anticoncepcionales y de prevención a las enfermedades sexualmente transmisibles, comienzan la vida sexual exponiéndose a riesgos. Sin embargo, ellos creen que se protegen de los riesgos inherentes al acto sexual, pero, por otra parte, afirman que los amigos no se comportan de dicha forma.

Palabras clave: Adolescencia. Sexualidad. Vulnerabilidad. Salud pública.

$\mathrm{O}$ interesse em pesquisar o pensamento de adolescentes a respeito do sexo e da sexualidade surgiu a partir da experiência em um Programa de Residência Multiprofissional em Saúde da Família, do qual participavam os autores deste trabalho. As atividades

1 Optamos por utilizar os termos meninos/meninas, garotos/garotas para descrever os adolescentes, tal qual eles próprios se referem ou são nomeados pelos profissionais de saúde e da educação com quem mantivemos contatos no decorrer da pesquisa. do Município, pois, segundo o Sistema de Informação da Atenção Básica (SIAB), Porto Velho registrou, em 2009, período da coleta de dados, um quantitativo de $27,90 \%$ de gestantes com idade abaixo de 20 anos, ou seja, mais de um quarto dos cadastros de gestantes no Município (Brasil, 2011). Essa mesma proporção aparece em dados mais recentes, fornecidos também pelo SIAB, pois, entre janeiro e junho de 2011, registraramse 1.143 gestações entre mulheres com até 20 anos incompletos, em um total de 4.216 cadastradas, ou seja, 27,11\% (Brasil, 2011).

Em um levantamento feito no Serviço de Arquivo Médico e Estatística (SAME) da Maternidade Municipal de Porto Velho a 
respeito dos registros de partos no período de julho de 2006 - quando ocorreu a inauguração dessa unidade - e junho de 2009 - período de coleta de dados desta pesquisa -, encontramos 10.585 partos registrados, vaginais e cesáreos, sendo 4.509 de mulheres com idade inferior a 20 anos, o que corresponde a $42,59 \%$ do total no citado. Nesse mesmo período, a maternidade fez o atendimento de 1.290 mulheres em situação de aborto, das quais 278 (21,55\%) tinham entre 13 e 19 anos.

Além desses dados, observou-se a inexistência de programas voltados para os adolescentes nas unidades de saúde onde era executado o programa de residência, com raras ações direcionadas especificamente para os jovens, pois a ênfase do trabalho das Equipes de Saúde da Família era dada a crianças, gestantes, idosos e, obviamente, às pessoas com problemas de saúde, como portadores de hipertensão e de diabetes. De tal maneira, uma adolescente, por exemplo, tornava-se alvo de atenção apenas se adoecesse ou engravidasse.

Em função dessas constatações, decidiu-se pesquisar o processo de iniciação sexual entre adolescentes moradores de uma das regiões onde o programa de residência era desenvolvido, tendo como objetivo conhecer a concepção desses jovens, na faixa etária dos 12 aos 17 anos, a respeito de questões acerca da sexualidade e de assuntos que estão a ela diretamente relacionados, como a gravidez precoce e as doenças sexualmente transmissíveis, além de verificar (1) como buscam orientação sobre esses assuntos, (2) como avaliam os riscos em suas primeiras experiências sexuais e (3) qual a sua opinião a respeito dos relatos dos amigos sobre esse mesmo assunto.

\section{A sexualidade na adolescência}

$\mathrm{Na}$ adolescência, são estabelecidos padrões básicos de comportamento que se perpetuam ao longo da vida, entre os quais aqueles pertencentes ao campo da sexualidade. Nesse momento de grandes transformações biopsicossociais, costuma ocorrer a iniciação sexual, muitas vezes sem a orientação prévia de um adulto responsável, que possibilitaria ao adolescente e à adolescente fazer escolhas conscientes, considerando desejo, prazer e riscos.

Pensar sobre a sexualidade na adolescência exige um olhar sobre os diversos sentidos que as descobertas e as mudanças, nessa etapa da vida, exercem sobre os gêneros, devendo-se considerar o tempo e o lugar em que ocorrem, pois é sobre esses aspectos que a cultura se impõe e passa a determinar práticas sociais e estilos de vida distintos.

Segundo Justo (2005), a adolescência é uma fase de passagem de um círculo social restrito - a família - para um universo social mais amplo que, frequentemente, passa a ter mais influência, sobretudo no que se refere aos membros do grupo ao qual está agregado ou que nele pretenda ser aceito. Para Moreira e Juarez (2004), a adolescência é um breve e marcante período de transição da infância para a vida adulta, decorrente de uma multiplicidade de mutações físicas, psicológicas e sociais, as quais tendem a provocar a percepção de que as necessidades imediatas devem ter prioridade sobre as possíveis consequências a longo prazo perante as decisões a serem tomadas, sobressaindo-se também sentimentos de invulnerabilidade e de onipotência.

Paralelamente a esse turbilhão de afetos, os adolescentes costumam ser instigados, por adultos e por seus pares, a definir suas relações afetivas, assim como a sua orientação religiosa e sexual. Destas, a questão sexual 
tende a preponderar na atualidade, o que torna as primeiras experiências não só um marco como também um rito de passagem, uma missão a ser cumprida para aceitação grupal (Vilela \& Doreto, 2006).

Brandão (2004) afirma que a iniciação sexual e/ou amorosa franqueia aos adolescentes a possibilidade do aprendizado da dimensão relacional íntima no tocante às diferenças de gênero, além de representar a conquista gradativa da autonomia pessoal nessa fase da vida. O autor destaca as questões de gênero como elementos que têm forte influência sobre os caminhos a serem percorridos, pois os processos educativos são distintos e estabelecem condições diferenciadas sobre como a temática é abordada pelos adultos - pais e professores, por exemplo -, ou mesmo por outros adolescentes. De tal forma, as posições sociais assimétricas encontradas entre os gêneros estão na base das representações atuais acerca das diferenças entre os sexos, com a forte crença de que ela é associada à valorização das práticas familiares, o que contribui para a manutenção das desigualdades entre homens e mulheres na sociedade (Poeschl, 2003).

Borges (2004), em uma pesquisa com os adolescentes da zona leste do Município de São Paulo (SP), ressalta que o início da vida sexual é um marco na vida de qualquer indivíduo e que é por ocorrer com maior frequência na adolescência, quando se está imerso em cobranças e imposições de todos os lados, que esse tema se torna tão delicado, demandando políticas públicas específicas. Em relação ao comportamento dos adolescentes masculinos, essa pesquisa destaca as declarações feitas por eles no sentido de que foram motivados às primeiras experiências sexuais devido à atração física pela parceira, embora nem sempre estivessem envolvidos emocionalmente. As adolescentes, por outro lado, destacaram que, ao iniciarem a vida sexual, estavam apaixonadas ou tinham algum vínculo com os parceiros.

Essa mesma variação no discurso entre os gêneros foi encontrada por Brandão, cujo trabalho enfatiza a assimetria entre os gêneros citando, como exemplo, a aquisição de hábitos preventivos à gravidez e as doenças sexualmente transmissíveis, que são raramente discutidos entre os parceiros, cabendo predominantemente às mulheres o ônus da preocupação, sobretudo no que diz respeito aos métodos contraceptivos. Devido a essa constatação, a autora sustenta que a menina/mulher deve ter autonomia, adquirindo conhecimento e poder sobre seu corpo.

Outra diferença entre os gêneros foi observada em uma pesquisa em Santa Catarina (Gubert \& Madureira, 2008) a respeito da iniciação sexual dos adolescentes masculinos. As autoras mostram que a precocidade das primeiras experiências sexuais ocorre em função da necessidade de autoafirmação da masculinidade, cuja meta é mostrar-se homem, além de haver a crença de que o homem não possui e não deve possuir controle sobre seus impulsos, pois, do contrário, pode ser considerado menos másculo.

Pensar sobre a sexualidade na adolescência é também refletir sobre seus riscos e sobre a educação recebida pela população jovem a respeito desse tema, pois o início da vida sexual do/a adolescente costuma ser um momento marcante, e é considerado por muitos, pelo menos no discurso, um dos passos para se atingir a plenitude pessoal. Contudo, esse início de inserção no universo adulto também insere o/a adolescente no campo das vulnerabilidades às doenças sexualmente transmissíveis (DST) e aos riscos de uma gestação não planejada. 
A intensidade dos riscos é proporcional ao clamor dos hormônios e dos discursos que estimulam a busca pelo prazer sexual a cada instante, nem sempre possibilitando antever que cuidados prévios são necessários e que há sempre consequências para os atos inconsequentes. Contudo, registra-se, tratase de um comportamento esperado de quem ainda está em pleno desenvolvimento da personalidade e precisa vivenciar, isto é, experimentar as demandas e as ofertas da vida antes de emitir algum juízo sobre elas.

\section{A sexualidade dos jovens brasileiros}

Para fins de interesse do presente estudo, destacamos duas pesquisas feitas pelo Ministério da Saúde a respeito do comportamento sexual dos jovens brasileiros, sendo uma delas realizada no final da década de 90 (Brasil, 1999) e a outra executada em 2008 e publicada no ano seguinte (Brasil, 2009). A primeira delas mostra que $55,6 \%$ dos jovens entre 16 a 25 anos, sexualmente ativos, declaravam não fazer uso de preservativo durante as relações sexuais. Na pesquisa feita em 2008, dos jovens de 15 a 24 anos, 30,1\% afirmaram não ter utilizado preservativo na primeira relação sexual. Além disso, 34,5\% desses jovens declararam ter praticado sexo antes dos 15 anos e $21,9 \%$ disseram ter tido mais de dez parceiros sexuais.

A consequência de os jovens não usarem a camisinha pôde ser medida em uma pesquisa conduzida por Taquette, Vilhena e Paula (2004). Nesse trabalho, realizado com 356 adolescentes de 12 a 19 anos que procuraram atendimento médico no Núcleo de Estudos da Adolescência da Universidade Estadual do Rio de Janeiro, foi encontrado entre eles $30,61 \%$ de casos com o histórico de DST. Outro dado importante dessa pesquisa foi a declaração de $22 \%$ dos pesquisados, com histórico de alguma doença venérea, que usavam álcool frequentemente, enquanto $20 \%$ desse mesmo grupo também usava alguma droga ilícita. Entre os jovens sem o registro de DST, tais índices foram bem menores, sendo 7,7\% usuários de álcool e 4\% usuários de drogas ilícitas. Conclui-se, portanto, que o uso de substâncias alteradoras da consciência implica um fator de risco para a infecção de alguma DST.

Assim, com base nesses números sobre o comportamento sexual dos adolescentes, surge a preocupação em entender suas concepções a respeito de tais assuntos, pois, em 2009, foram identificados 3.398 casos de AIDS em jovens de 13 a 24 anos, com uma taxa de detecção, por 100.000 habitantes, de 7,5 casos para o sexo feminino e de 9,1 casos para o sexo masculino, mantendose essa média desde 1998, inferior à taxa de incidência da população brasileira, em geral, que era de 20,1/100.000 habitantes no mesmo período (Brasil, 2010).

Outro fator importante quando se discute o comportamento sexual entre jovens é o índice elevado de gravidez entre adolescentes, pois, conforme mostramos no início deste trabalho, no Município de Porto Velho, local onde foi realizada esta pesquisa, as notificações de gestação entre mulheres com menos de 20 anos superam um quarto dos registros. Além disso, os dados sobre os partos na maternidade pública, que atende uma população de baixa renda, apresentam mais de $40 \%$ das parturientes dentro dessa faixa etária.

Nesse sentido, Silva (2004) e Meincke (2007) discutem as consequências psicológicas e sociais resultantes de gestações não planejadas, pois, em muitos casos, trata-se de meninas sem apoio familiar e que não possuem uma rede de suporte social e emocional. A gravidez e a criança passam a 
ser um problema a mais para a adolescente e para a sua família, e geram desconfortos e conflitos. Em função disso, a Organização Mundial de Saúde (OMS) reforça a diretriz de que é preciso ter estratégias para a promoção da saúde com enfoque na educação profilática, com políticas que estimulem ações comunitárias e orientações em serviços de atenção básica (Atkins, Best, \& Shapiro, 2001).

\section{Método e materiais}

Este é um estudo exploratório, de natureza descritiva, no qual os dados obtidos foram analisados por meio de variáveis quantificáveis e qualificáveis. O perfil dos pesquisados, a frequência e a classificação dos dados foram construídos por meio de um tratamento estatístico, com a ajuda do aplicativo Microsoft Office Excel (2007). Para a análise qualitativa, foi empregada a técnica de análise de conteúdo temático-categorial (Bardin, 2002), que permite decompor o objeto investigado sob a ótica dos relatos apresentados pelos participantes. A análise dos resultados está fundamentada em estudos que envolvem o comportamento sexual dos adolescentes e as políticas de saúde do governo (Brasil, 2009; Farias, 2010; Silva, 2004; Velho \& Souza, 2003; Spindola \& Silva, 2009; Altmann, 2009; Meincke, 2007; Poeschl, 2003).

Para Richardson (1999), a etapa quantitativa nessas condições de pesquisa é caracterizada pela representação de um nível de análise que permite identificar as características dos fenômenos e que possibilita também a sua ordenação e a sua classificação. Seguindo esse raciocínio, o tratamento dos dados qualitativos foi realizado por meio da análise de conteúdo do tipo categorial, por ser a junção de técnicas de análise das comunicações, visando a obter, por procedimentos objetivos e sistemáticos, a descrição do conteúdo das respostas e os indicadores (quantitativos ou não). A técnica empregada neste estudo para a análise qualitativa permite a análise da comunicação verbal ou escrita bem como o acesso a diversos conteúdos presentes em um texto.

Nesse sentido, a apreciação dos aspectos qualitativos das informações coletadas foi realizada por meio da técnica de análise de conteúdo, conforme definida por Bardin, que estabelece algumas etapas para o alcance de resultados das análises: pré-análise; exploração do material ou codificação, tratamento dos resultados, inferência e interpretação. Nesta pesquisa, os dados analisados partiram de temas extraídos de perguntas que abordavam aspectos sobre a vida afetiva, as experiências sexuais e a gravidez na adolescência. Procurou-se abstrair temas recorrentes, que permitissem alguma inferência de conhecimentos relativos às condições de produção/ recepção dos conteúdos das mensagens organizadas em discursos assemelhados ou dissonantes, formando assim categorias (Bardin, 2002; Turato, 2005; Flick, 2009).

A pesquisa foi realizada em uma escola de ensino fundamental e médio, localizada em uma comunidade da zona leste de Porto Velho, dentro da área de abrangência da unidade de saúde em que eram desenvolvidas as atividades da Residência Multiprofissional em Saúde da Família. Na época da pesquisa, essa escola possuía o maior contingente de alunos da região, com 1.149 discentes matriculados em 2009, incluindo turmas de educação de jovens e adultos (EJA).

O território onde se localiza a escola é composto por três grandes comunidades, pertencentes a bairros com precárias condições de saneamento básico, cuja média de renda mensal não ultrapassava um salário mínimo. A faixa etária populacional 
é predominantemente formada por adolescentes e adultos jovens (Porto Velho, 2008).

A população estudada é formada por adolescentes de ambos os sexos, com idade entre 12 e 17 anos, sendo esse o primeiro critério de inclusão, justificado por se tratar do período em que a maior parte das pessoas atinge a puberdade e inicia a vida sexual, pois, conforme dados de uma pesquisa feita pelo Ministério da Saúde, 34,5\% dos jovens brasileiros começaram a ter contatos sexuais antes dos 15 anos (Brasil, 2009). Além disso, pelo menos do ponto de vista jurídico, é a partir dos 18 anos que o adolescente pode ser considerado adulto e responsabilizado pelos seus atos. De tal forma, a escolha da faixa etária entre 12 e 17 anos visava a abranger o período em que dificilmente um adolescente será percebido, por ele próprio ou por outrem, como criança ou adulto.

Para contatar essa população que seria pesquisada e constituir a amostra, foi realizado um levantamento na secretaria da escola, após autorização da direção, que informou a existência de 122 alunos dentro da faixa etária de interesse do estudo, sendo 50 do sexo masculino e 72 do sexo feminino, todos matriculados entre o $7^{\circ}$ ano do ensino fundamental e o $2^{\mathrm{o}}$ ano do ensino médio.

Com base nessas informações, foi solicitada autorização do Comitê de Ética na Pesquisa com Seres Humanos (CEP), do Núcleo de Saúde da Universidade Federal de Rondônia, acrescentando como critério de inclusão, além da faixa etária, a concordância de cada aluno e a autorização de seus responsáveis legais, por meio da assinatura do Termo de Consentimento Livre e Esclarecido (TCLE).

O primeiro passo, após aprovação da pesquisa pelo CEP (FR no 220915; CAAE $\mathrm{n}$-0008.0.047.000-08), foi reunir-se novamente com a direção da escola e, posteriormente, com os pais e professores, para explicar os objetivos da pesquisa e seus procedimentos, salientando que a participação era voluntária, sem qualquer ônus para os pais e alunos e para a escola. Em caso de recusa ou desistência, não haveria qualquer prejuízo para a vida escolar dos participantes, sendo garantidos o sigilo e o anonimato das informações colhidas.

Concluída essa etapa dos procedimentos, dirigimo-nos às salas de aula para entrar em contato com os alunos, quando houve a distribuição do TCLE, reforçando que deveria ser entregue aos seus responsáveis legais para que pudesse ser lido, analisado e, caso concordassem, assinado. No mesmo dia da entrega dos TCLE, foi acordada a data para um novo encontro e para a devolução desse documento, quando seria aplicado o questionário.

De tal forma foi procedido no dia combinado, e, conforme os alunos apresentavam os TCLE assinados por seus responsáveis legais, recebiam os questionários com as orientações sobre como responder, ressaltando que não deveriam identificar-se nominalmente.

As aplicações foram coletivas, no final do primeiro semestre de 2009, e tiveram duração média de 30 minutos. Foram necessários dois dias para as aplicações nas diferentes turmas, que contaram com a participação dos 52 alunos que compõem o quadro de participantes da amostra.

O instrumento utilizado foi um questionário semiestruturado, com 22 perguntas (fechadas e abertas), divididas em quatro partes: 1) aspectos socioeconômicos, 2) aspectos da vida afetivo-amorosa, 3) conhecimento sobre métodos contraceptivos e 4) vida sexual dos adolescentes. 


\section{Resultados e discussão}

\section{Perfil dos sujeitos da pesquisa}

Dos 52 adolescentes que participaram da pesquisa, metade cursava o ensino fundamental, e a outra parte, os dois primeiros anos do ensino médio. Em relação à faixa etária, 35\% tinham entre 12 a 14 anos, e 65\% estavam na faixa etária dos 15 aos 17 anos. Quanto ao gênero, $65,4 \%$ são do sexo feminino e $34,6 \%$, do sexo masculino. Tal amostra segue proporcionalmente os números fornecidos pela secretaria da escola a respeito das classes de ensino abordadas, referentes ao ano letivo de 2009.

A Tabela 1, a seguir, apresenta o perfil dos adolescentes pesquisados e mostra com quem residem: pai, mãe ou outras pessoas. Predominaram os que moram com ambos os genitores $(59,6 \%)$, sendo que $27 \%$ declararam morar apenas com a mãe. Quanto à renda familiar, predominam aqueles $(44,2 \%)$ cuja somatória de recursos financeiros da família não ultrapassa dois salários mínimos mensais, corroborando os dados oficiais sobre o baixo poder econômico da população local (Porto Velho, 2008).

Tabela 1. Número de adolescentes entrevistados, segundo características sociodemográficas

\begin{tabular}{|c|c|c|}
\hline Variável & $\mathrm{N}$ & $\%$ \\
\hline TOTAL GERAL & 52 & 100 \\
\hline Sexo & $\mathrm{N}$ & $\%$ \\
\hline Masculino & 18 & 34,6 \\
\hline Feminino & 34 & 65,4 \\
\hline Mora com & $\mathrm{N}$ & $\%$ \\
\hline Mãe & 14 & 27,0 \\
\hline Pai & 1 & 1,9 \\
\hline Pai e mãe & 31 & 59,6 \\
\hline Nenhum dos dois & 6 & 11,5 \\
\hline Nível de estudo & $\mathrm{N}$ & $\%$ \\
\hline Ensino fundamental ( 7 o ao 9o ano) & 26 & 50 \\
\hline Ensino médio ( 1 o e $2^{\circ}$ ano) & 26 & 50 \\
\hline Renda familiar & $\mathrm{N}$ & $\%$ \\
\hline Entre 1 e 2 salários mínimos & 23 & 44,2 \\
\hline Entre 3 e 4 salários mínimos & 7 & 13,5 \\
\hline Igual e/ou maior que cinco salários mínimos & 2 & 3,8 \\
\hline Não informado ou não sabe & 20 & 38,5 \\
\hline Escolaridade dos pais & $\mathrm{N}$ & $\%$ \\
\hline Não foi à escola & 10 & 9,6 \\
\hline Ensino fundamental & 40 & 38,5 \\
\hline Ensino médio & 19 & 18,3 \\
\hline Fez ou faz faculdade & 4 & 3,8 \\
\hline Não sabe $\quad 31$ & & \\
\hline
\end{tabular}

O perfil dos adolescentes pesquisados pode ser resumido em pessoas pertencentes a classes sociais desfavorecidas, com renda familiar que não supera dois salários mínimos, e cujos pais, em 
sua maioria, cursaram até o ensino fundamental, mas muitos não concluíram esse nível escolar e estão limitados a ofertas de empregos/ocupações que os impedem de alcançar melhoria salarial.

\section{Aspectos da vida afetivo-sexual: fontes de informação e apoio}

Foi perguntado qual meio utilizam para obter informações sobre sexo. Entre os meninos ${ }^{1}$, prevaleceu a resposta $(61,1 \%)$ de que os pais seriam a principal fonte de informação; entre as meninas, 52,9\% declararam utilizar livros e revistas para essa finalidade, e 38,2\% afirmaram também recorrer aos pais. Como a pergunta permitia mais de uma resposta - conforme pode ser verificado na Tabela 2 - há também o registro de fonte de informações como a internet e profissionais da saúde ou da educação, dentre outras, porém com números menos expressivos.

Tabela 2. Distribuição dos adolescentes segundo fonte de informação sobre sexo

\begin{tabular}{lllll}
\hline & \multicolumn{4}{c}{ Adolescentes } \\
& Meninos & Meninas & \\
Meio procurado & Respostas & $\%$ & Respostas & $\%$ \\
\hline Pai e mãe & 11 & $61,1 \%$ & 13 & $38,2 \%$ \\
Outros familiares ou parentes & 0 & 0 & 7 & $20,5 \%$ \\
Professores/escola & 2 & $11,1 \%$ & 1 & $2,9 \%$ \\
Profissionais de saúde/agente & & & & \\
comunitário (ACS) & 2 & $11,1 \%$ & 1 & $2,9 \%$ \\
Livros, revistas & 7 & $38,8 \%$ & 18 & $52,9 \%$ \\
Internet & 4 & $22,2 \%$ & 6 & $17,6 \%$ \\
Amigos/colegas & 2 & $11,1 \%$ & 8 & $23,5 \%$ \\
Ninguém & 3 & $16,6 \%$ & 4 & $11,7 \%$ \\
Outros & 0 & 0 & 1 & $2,9 \%$ \\
\hline
\end{tabular}

Obs.: questão com mais de uma resposta possível

A fonte de informação sobre sexo mencionada pelos adolescentes foi uma surpresa. Os meninos afirmaram que preferem recorrer aos pais para obter informações, e isso destoa do que se sabe sobre os adolescentes, sobretudo os do sexo masculino, pois os primeiros trabalhos sobre a adolescência, no início do século XX até as publicações mais recentes, apontam que a dinâmica dessa idade é que a voz do grupo prepondera sobre os conselhos familiares. Além disso, culturalmente, os indivíduos do sexo masculino são mais resistentes, e até mesmo arredios, no que se refere à busca por orientação (Moreira \& Juarez, 2004).

Entre as meninas, os dados foram parecidos, porém destacaram que procuram informações sobre sexo, preferencialmente, em revistas e livros, citando os pais em segundo plano. Apesar de a pesquisa não fazer tal detalhamento, é possível imaginar que as adolescentes recorram às mães para tirar dúvidas e sejam orientadas sobre ciclo menstrual, higiene íntima ou problemas ginecológicos. Livros e revistas, contudo, acabam desempenhando um papel importante, pois alguns deles são escritos e orientados para o público juvenil feminino. Esse indicativo da preferência das meninas sugere que os programas de esclarecimento por meio de políticas públicas que têm o objetivo de alcançar esse segmento precisam ser elaborados dentro desse modelo informativo, pois esse talvez seja um importante veículo para atingir o grupo de pessoas 
em questão. Para tanto, o material deve dispor de uma linguagem apropriada, como fazem muitas revistas destinadas ao público adolescente feminino, mas deve-se ter em conta que, certamente, nem todas as adolescentes, sobretudo as de família de baixa renda, têm condições de utilizá-lo.

Quando perguntadas sobre o tipo de ocupação da pessoa com a qual prefeririam se informar ou conversar sobre sexo (Tabela 3), 41,17\% das meninas disseram que escolheriam alguém do mesmo sexo, 32,35\% citaram pessoas mais velhas e $26,47 \%$ mencionaram um profissional de saúde como a pessoa adequada para transmitir tais informações. Para os adolescentes do sexo masculino, houve prevalência de respostas que afirmaram preferir falar sobre sexo com alguém que imaginem conhecer o assunto (38,88\%), seguidas de $27,77 \%$ das respostas nas quais declararam acreditar que os profissionais de saúde sejam fontes confiáveis para tratar do tema. Diferentemente das meninas, que mencionaram uma predileção por pessoas do mesmo sexo, os meninos apresentaram essa opção em terceiro lugar, com o índice de $(22,2 \%)$ de citações.

Tabela 3. Distribuição dos adolescentes segundo o tipo de pessoa que, se pudessem, escolheriam para orientar sobre sexo

\begin{tabular}{|c|c|c|c|c|}
\hline \multirow[b]{3}{*}{ Meio procurado } & \multicolumn{4}{|c|}{ Adolescentes } \\
\hline & \multicolumn{2}{|c|}{ Meninos $(\mathrm{N}=18)$} & \multicolumn{2}{|c|}{ Meninas $(N=34)$} \\
\hline & Respostas & $\%$ & Respostas & $\%$ \\
\hline Um religioso & 2 & 11,11 & 3 & 8,82 \\
\hline Um profissional de educação & 2 & 11,11 & 1 & 2,94 \\
\hline Um profissional da saúde & 5 & 27,77 & 9 & 26,47 \\
\hline \multicolumn{5}{|l|}{ Alguém experiente, que conhece } \\
\hline sexo na prática & 7 & 38,88 & 5 & 14,70 \\
\hline Alguém do mesmo sexo & 4 & 22,22 & 14 & 41,17 \\
\hline Alguém de sexo diferente & 2 & 11,11 & 4 & 11,76 \\
\hline Alguém mais velho & 4 & 22,22 & 11 & 32,35 \\
\hline Alguém de idade mais próxima a sua & 2 & 11,11 & 3 & 8,82 \\
\hline Outro tipo de pessoa não citada acima & 2 & 11,11 & 2 & 5,88 \\
\hline
\end{tabular}

Obs.: questão com mais de uma resposta possível

Um estudo etnográfico sobre educação sexual, gravidez e prevenção, desenvolvido entre agosto de 2002 e julho de 2003 em uma escola municipal da cidade do Rio de Janeiro, revelou que as intervenções escolares buscavam desenvolver nos adolescentes um sentido de responsabilidade em torno das relações sexuais, visando a mudar ou a adequar os dispositivos que estruturam os comportamentos preventivos. No entanto, as informações sobre métodos anticoncepcionais estavam relacionadas às questões dos adultos, e permanecem distantes dos adolescentes, sem reconhecer as peculiaridades dessa fase da vida (Altmann, 2009).

Com base nessas informações e considerando as respostas nos questionários desta pesquisa, conclui-se que é necessário maior contato com o universo dos adolescentes para que haja melhor comunicação. Desse modo, pode-se tornar viável o compartilhamento das questões de foro íntimo, tal como se espera seja desenvolvido por profissionais de saúde e/ou da educação. 
Seguindo esse raciocínio acerca do apoio que o adolescente possa receber a respeito de seus interesses e necessidades dentro do campo sexual, o questionário trazia uma pergunta sobre o local ou a pessoa que eles/elas procuram quando precisam saber sobre o uso de algum contraceptivo ou quando necessitam adquiri-lo (Figura 1). As adolescentes afirmaram adquirir anticoncepcionais, incluindo camisinhas, em drogarias - em um total de $68 \%$ das respostas. Em segundo lugar, apareceu a Unidade Básica de Saúde (UBS), com 41\% das respostas, salientando que a questão permitia mais de uma opção a ser assinalada.

Entre os adolescentes do sexo masculino, houve o mesmo padrão de respostas, com um índice de $78 \%$ de meninos assinalando que buscam meios anticoncepcionais em farmácias e drogarias, enquanto as UBS foram citadas em $61 \%$ das respostas. Profissionais de saúde, como os agentes comunitários (ACS), apareceram em terceiro lugar para ambos os sexos, com $22 \%$ citados entre os meninos e $35 \%$ entre as meninas.

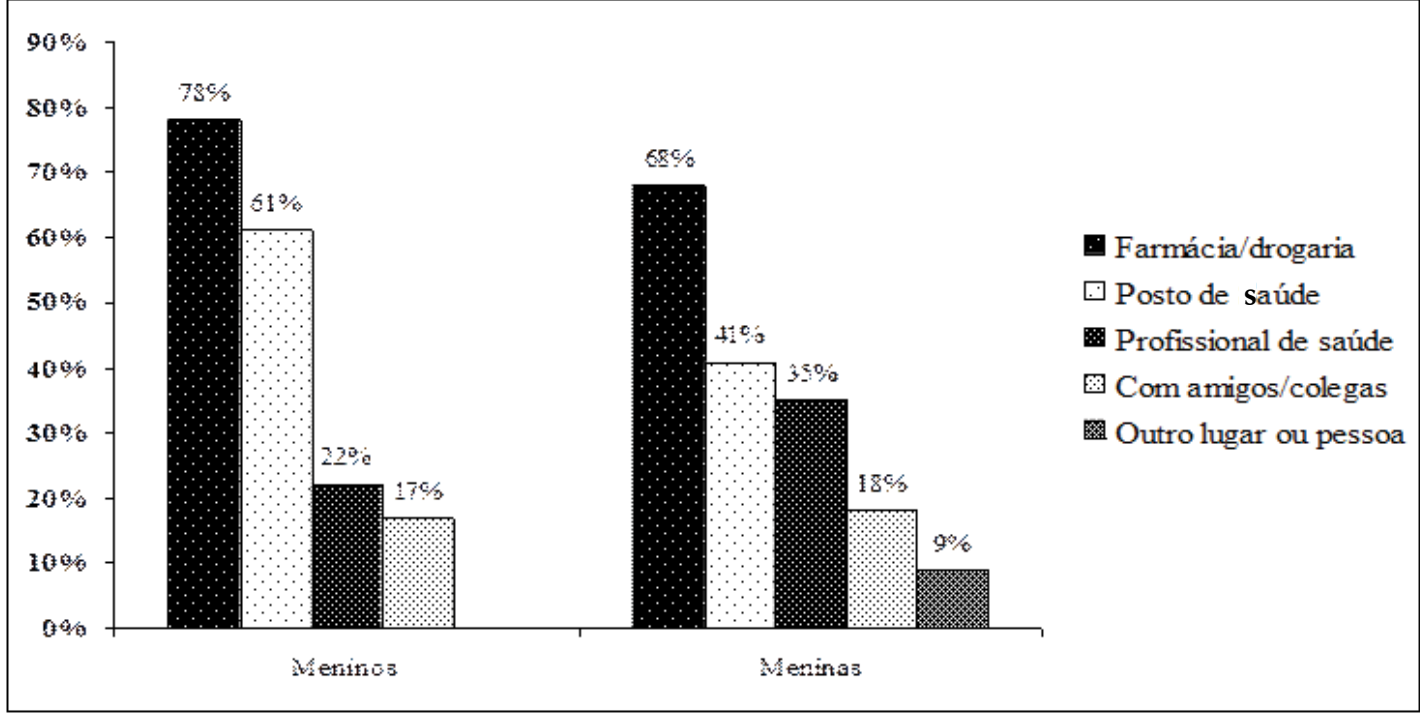

Figura 1. Quem ou onde os adolescentes procuram para adquirir algum método anticoncepcional

Esses dados mostram que os adolescentes preferem, talvez por falta de opção, recorrer a farmácias ou a drogarias para adquirir anticoncepcionais, embora as políticas públicas preconizem que as escolas podem fazer isso e que as UBS são os lugares de referência, sobretudo para comunidades carentes, como é o caso, para a aquisição de informações e de métodos contraceptivos ou preventivos às DST. No que se refere ao local estudado, encontramos uma situação em que o poder público tem se omitido ou tem falhado com os adolescentes.

\section{Avaliação dos adolescentes sobre os riscos e as consequências do sexo}

A pesquisa também abordou questões relativas à concepção que os adolescentes possuem dos riscos inerentes ao ato sexual, oferecendo questões em que pudessem opinar sobre eles próprios e sobre os jovens em geral. Quando indagados sobre alguma situação vivida em consequência da relação sexual, tais como gravidez indesejada ou uma DST, seja para si mesmos ou para alguém que conhecessem, apareceram, no cômputo total, 28\% dos meninos e 9\% das meninas 
que declararam ter tido pelo menos uma gravidez indesejada em função de não terem usado métodos anticoncepcionais (Figura 2); em números absolutos, foram 5 rapazes, dentro de um universo de 18 participantes, e 3 garotas, dentre as 34 que responderam ao questionário. Com relação a terem uma amiga que tivesse engravidado ou a um amigo que tivesse provocado uma gravidez sem ter planejado, o resultado foi idêntico: $56 \%$ para ambos os sexos. Além disso, $22 \%$ dos meninos e $12 \%$ das meninas afirmaram ter conhecimento de um/a amigo/a que contraiu alguma DST.

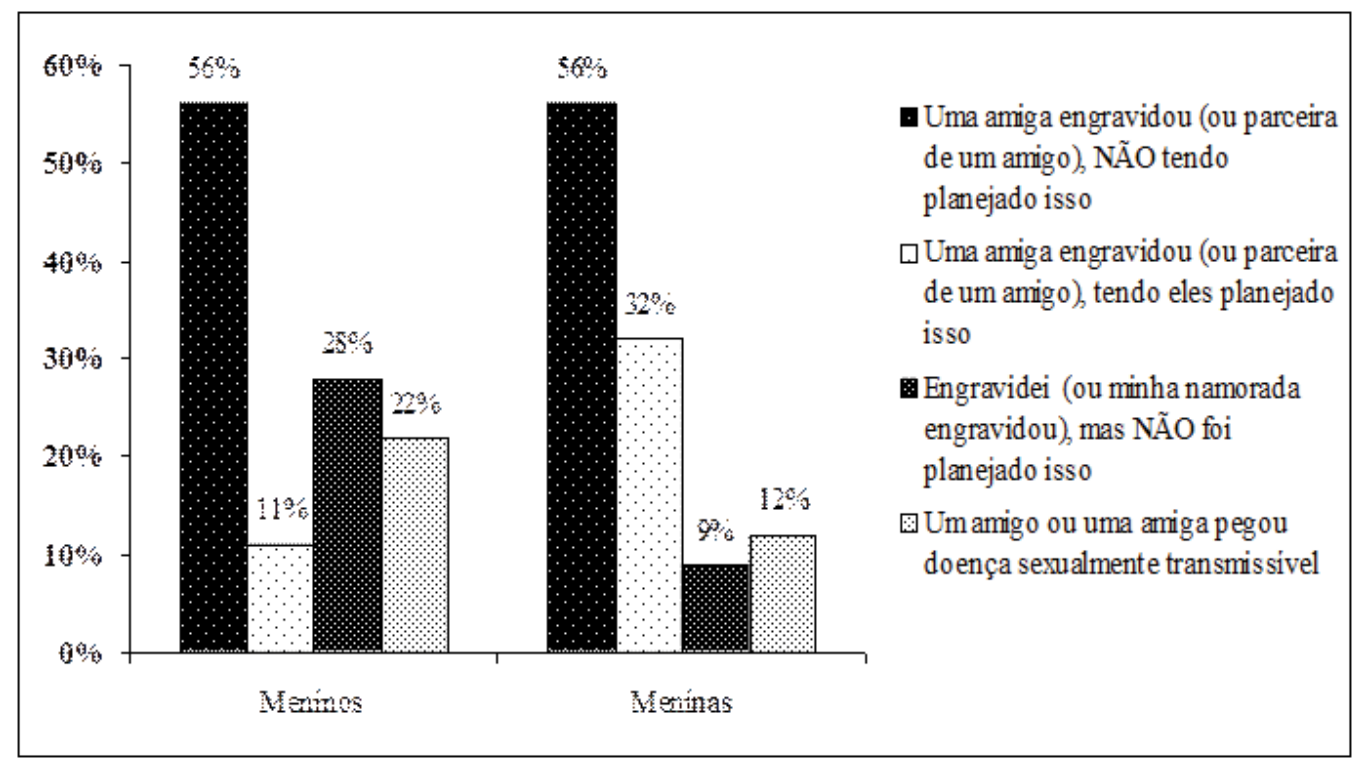

Figura 2 . Consequências do sexo que vivenciaram ou conhecem alguém que vivenciou

Um dado importante, ainda da Figura 2, é o fato de aparecer em $11 \%$ das respostas dos rapazes, e de $32 \%$ das garotas, a afirmação que conhecem um amigo (ou amiga) que engravidou intencionalmente. Sobre tal questão, havia no questionário uma pergunta aberta a respeito de meninas que engravidam intencionalmente, sobre a qual se discutirá mais adiante.

No que se refere à gestação indesejada entre as adolescentes (Figura 3), os rapazes afirmaram que, entre as causas principais, estaria o fato de elas não conseguirem controlar o desejo de fazer sexo ( $72 \%$ das respostas) ou porque não imaginavam que engravidariam ( $61 \%$ das respostas). Não saber usar a camisinha, ou não gostar de usá-la, foi apontado como uma das causas para 44\% dos questionários respondidos pelos meninos - para ambas as respostas. Além disso, também foi citado não terem dinheiro para comprar os contraceptivos, conforme assinalaram $17 \%$ dos adolescentes masculinos - ressaltando que poderiam apontar mais de uma causa para essa questão. Na opinião das adolescentes sobre essa mesma indagação, predominou a resposta que as meninas que engravidam sem planejar não conhecem ou não sabem usar os contraceptivos (65\% das respostas), enquanto $62 \%$ também consideraram a crença que elas teriam de não imaginar que o sexo desprotegido pudesse trazer tal consequência. O terceiro fator mais citado foi que não gostariam de usar o preservativo (56\%), seguido de $47 \%$ menções ao desejo incontrolável como a razão para fazerem sexo, mesmo sabendo dos riscos. Por fim, tal como aconteceu com 
os meninos, houve pouca menção à falta de dinheiro como causa para gravidez não planejada (6\% das respostas).

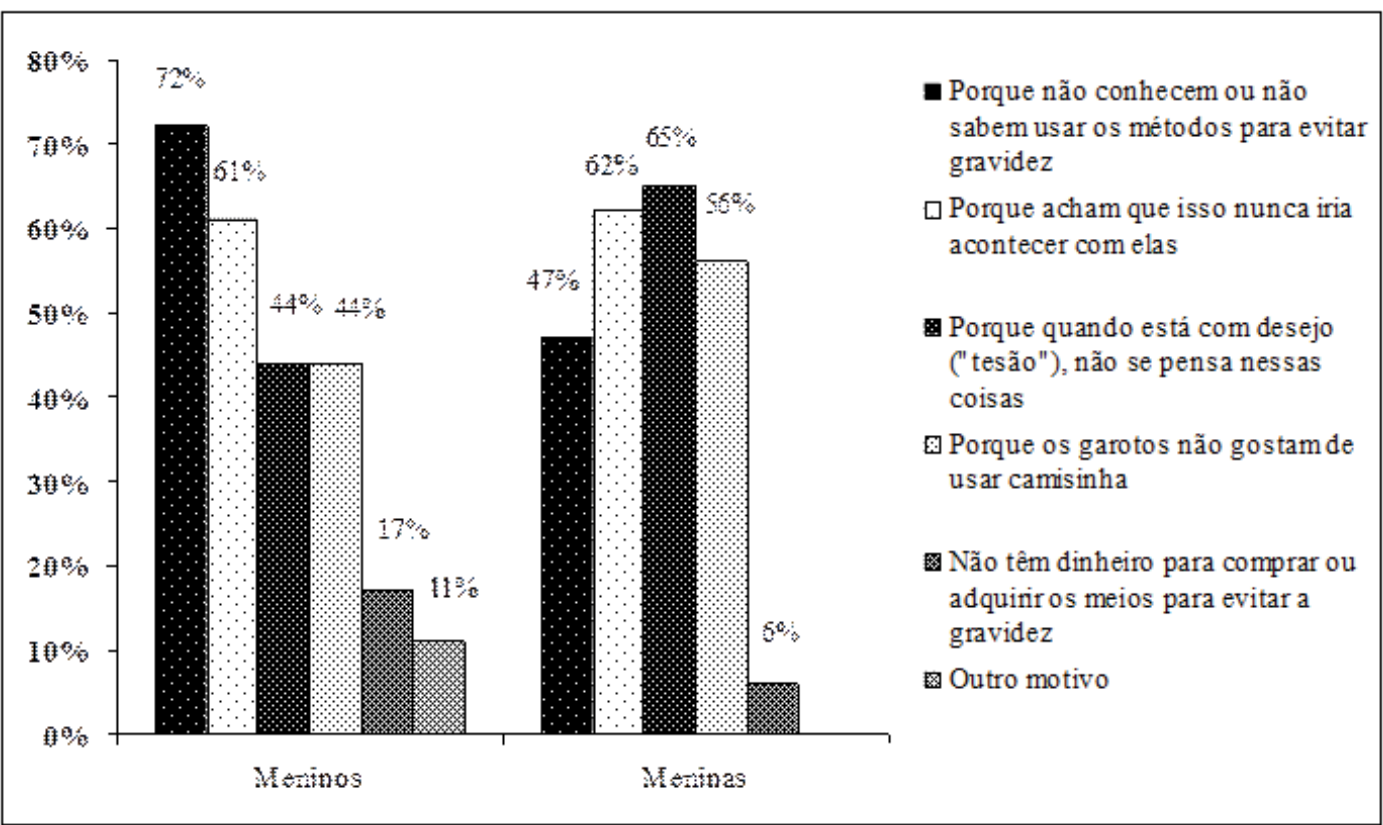

Figura 3. Opinião sobre os motivos que levam algumas garotas a engravidar, mesmo não querendo ter filhos

Ainda com referência à prevenção, diante das escolhas que precisam ser adotadas no momento do sexo, foi proposto aos participantes da pesquisa (Figura 4) um dilema. A questão posta tratava de uma situação hipotética em que haveria a possibilidade de sexo, mas sem camisinha à disposição. O que fariam?

Meninos e meninas responderam predominantemente que não fariam sexo para poder evitar as consequências indesejáveis, sendo $85 \%$ das meninas e $67 \%$ dos meninos. Tais números denotam que há consciência dos riscos implícitos ao ato sexual e que, pelo menos do ponto de vista discursivo, uma situação como a proposta seria resolvida assertivamente. Por outro lado, houve também respostas no sentido de ignorar os riscos, sobretudo em relação às DST, pois, entre as meninas, verifica-se o registro de $18 \%$ das respostas que indicam o uso da pílula do dia seguinte. 


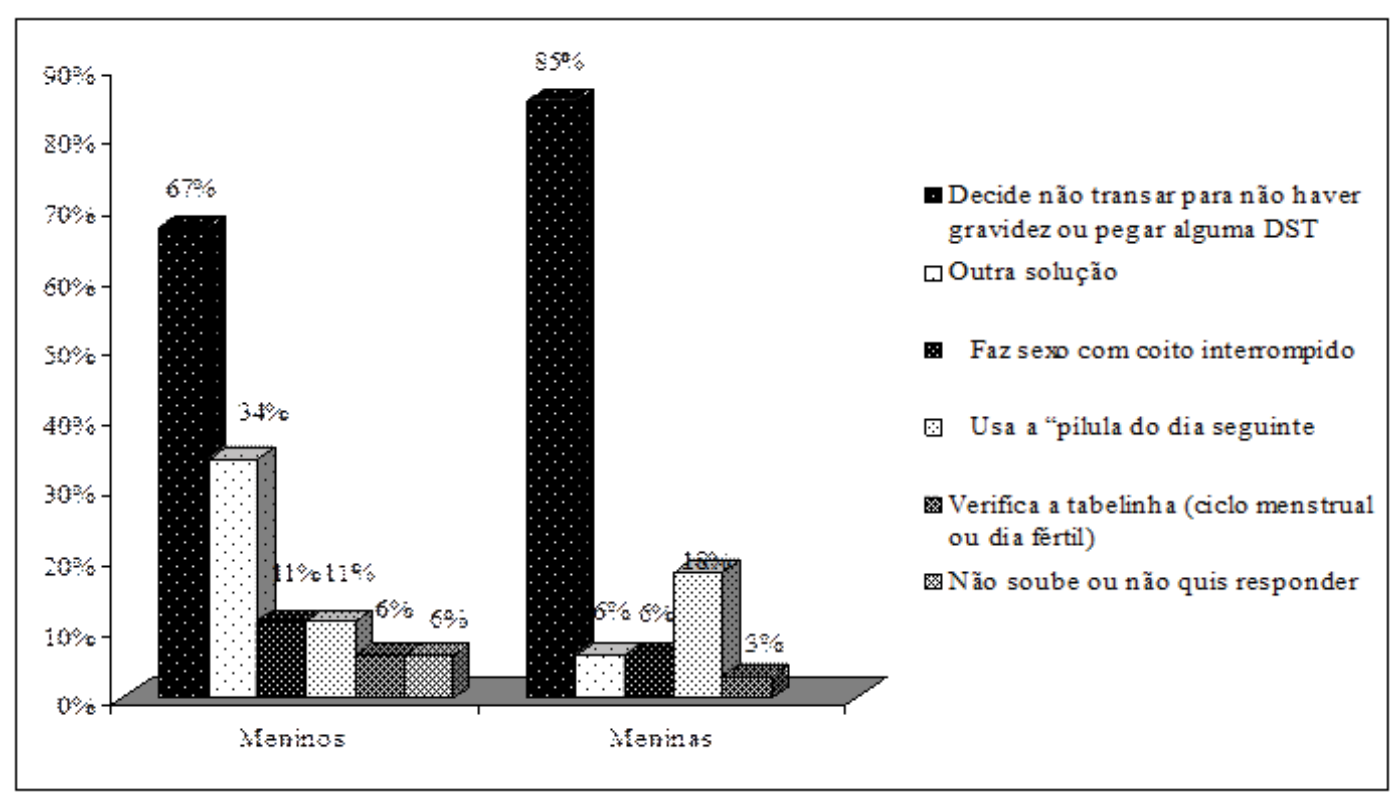

Figura 4. Dilema: reação diante de uma possibilidade de sexo, mas de não haver camisinha (mais de uma resposta possível)

Sabedores de que discurso e ações sexuais nem sempre são congruentes entre si e de que é preciso ter reservas sobre as opiniões manifestadas sobre esse assunto, esta pesquisa optou por trazer questões para os respondentes avaliarem o comportamento de colegas e amigos, como forma de respostas para além dos clichês, pois, quando se refere a si mesmo, quem responde um questionário de ordem íntima tende a opinar de acordo com o politicamente correto, tecendo respostas que se supõe serem mais adequadas. Nesse sentido, foi elaborada uma questão, cujo resultado aparece na Figura 5, de temática semelhante ao dilema exposto na Figura 4. No caso, o dilema era colocado como se tivesse sido vivenciado por outra pessoa.

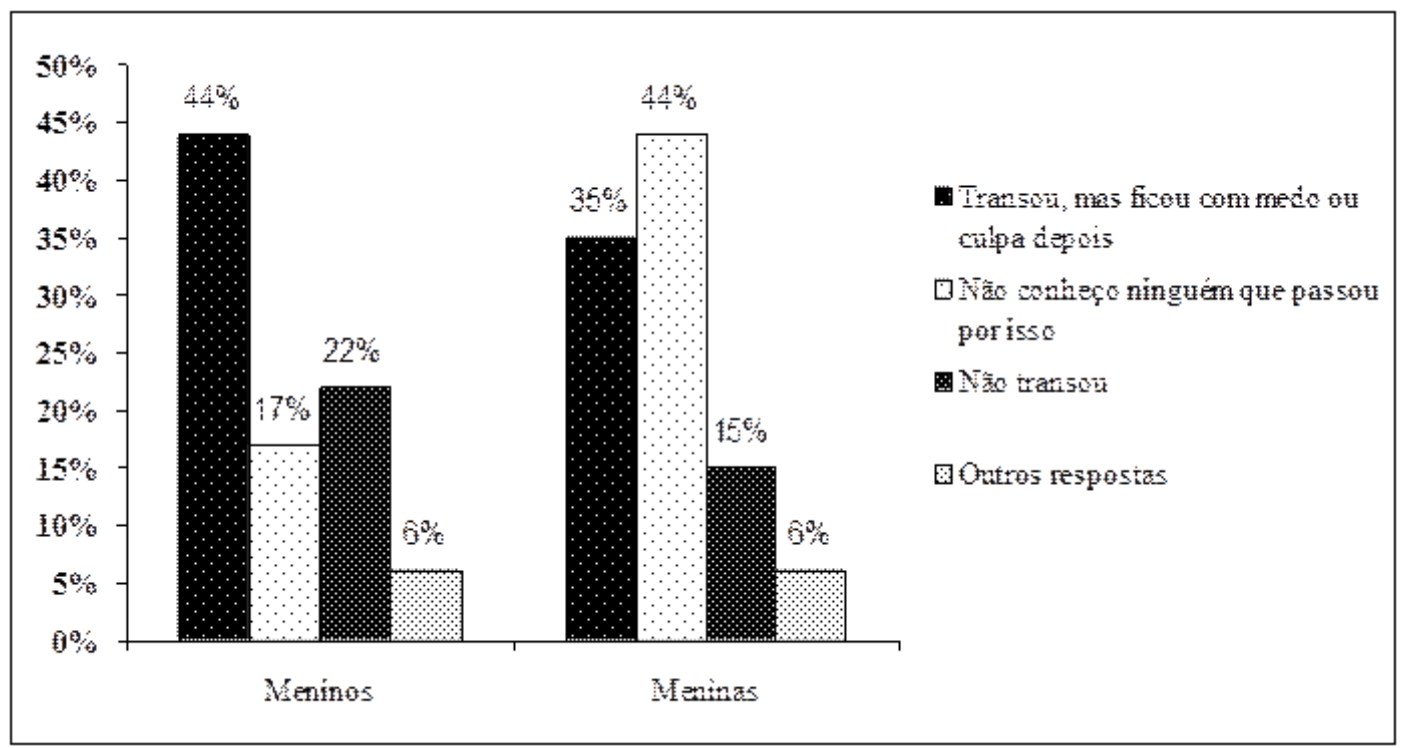

Figura 5. Distribuição das respostas à pergunta "Conhece alguém que, numa situação de possibilidade de sexo, não tinha camisinha, e qual foi a escolha?" 
Nessa questão, as respostas também foram distintas entre os gêneros. Entre as respostas masculinas, predominaram (44\%) aquelas que afirmavam que o/a amigo/a, nessa situação, havia optado por fazer sexo. Ainda entre os meninos, $22 \%$ afirmaram que o/a conhecido/a havia optado por não transar, enquanto $17 \%$ afirmaram desconhecer alguém que tenha passado por essa situação. Entre as meninas, esse tipo de resposta, ou seja, que desconhecem alguém que tenha passado por esse tipo de episódio, foi predominante, com $44 \%$ das respostas. Contudo, $35 \%$ delas afirmaram conhecer alguém que optou por fazer sexo, e 15\% disseram que a pessoa conhecida optou por não transar.

Tais resultados, quando comparados com os outros dados (Figura 4), indicam que os adolescentes se autoavaliam como pessoas que adotam hábitos preventivos e tomam atitudes assertivas perante o sexo, mas que o mesmo não ocorreria com seus colegas e amigos. Os adolescentes demonstram conhecer a importância da prevenção, listando os benefícios em adotá-la nas relações sexuais, e, quando postos diante do dilema de praticar ou não sexo, não tendo à disposição esse preservativo, afirmam que não o fariam. No entanto, quando perguntados se sabiam de um/a amigo/a que teria sofrido as consequências do sexo desprotegido (Figura 2), a porcentagem de afirmações positivas foi elevada. Além disso, quando se coloca o dilema em que um/a amigo/a decidiu ignorar os riscos e praticar sexo sem proteção, afirmam que eles se expuseram aos riscos.

Indagando-se sobre os conhecimentos de que os adolescentes dispõem sobre métodos anticoncepcionais, os meninos (Figura 6) afirmaram conhecer, em primeiro lugar, o preservativo masculino, em $88,8 \%$ das respostas; em seguida, citam a camisinha feminina $(77,7 \%)$ e a pílula $(55,5 \%)$ - ressaltando que poderiam dar mais de uma resposta para a mesma questão. As meninas (Figura 7) indicam, em primeiro lugar, a pílula anticoncepcional, com 91,1\% de citações, seguida da camisinha masculina $(88,2 \%)$ e da camisinha feminina: $67,7 \%$ das respostas.

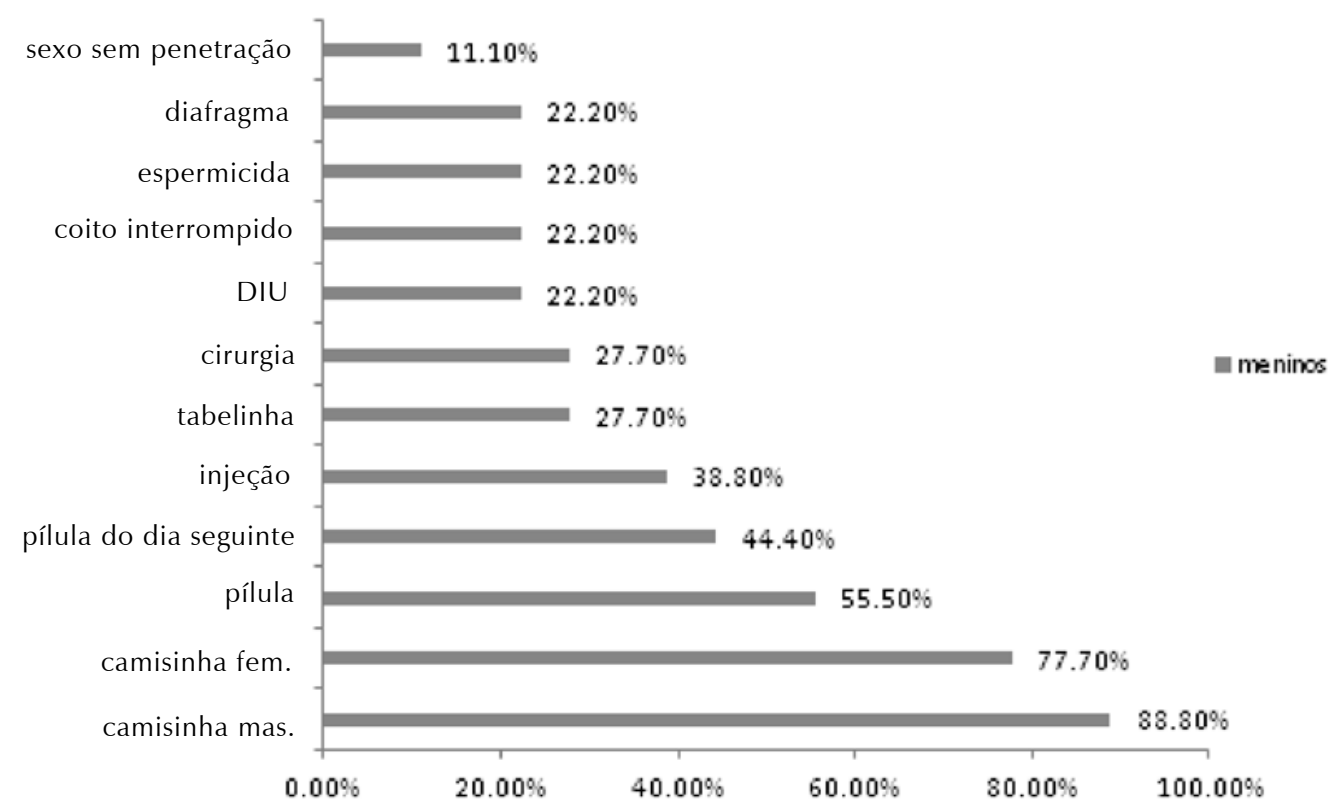

Figura 6. Distribuição de métodos anticoncepcionais citados pelos adolescentes do sexo masculino (Obs.: Questão com mais de uma resposta possível) 


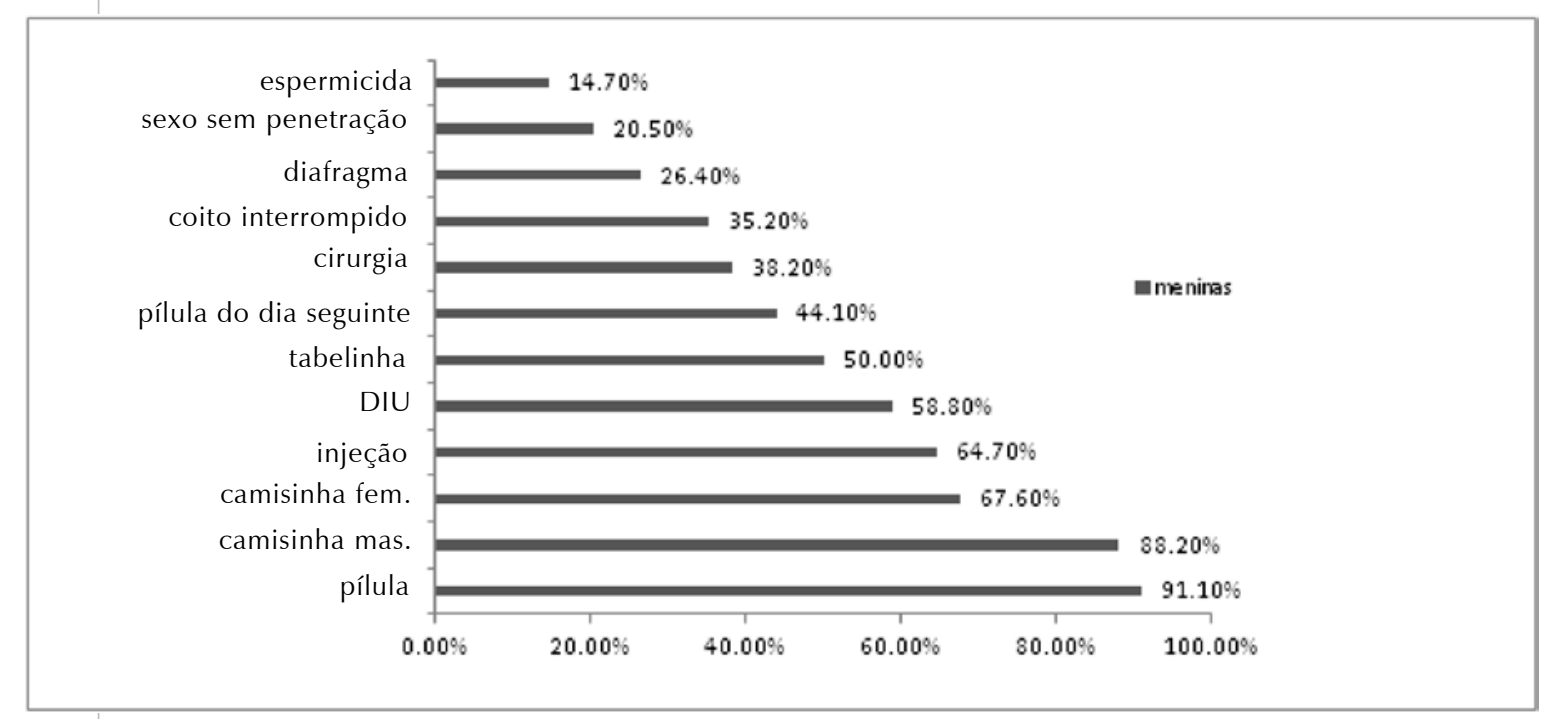

Figura 7. Distribuição de métodos anticoncepcionais citados pelas adolescentes. (Obs.: Questão com mais de uma resposta possível)

\section{Vida afetiva: eles querem pegar/ficar; elas querem namorar/casar}

Com relação às questões não estruturadas, nas quais os adolescentes discursavam sobre o tema proposto a partir de perguntas abertas, diferentes significados contidos no texto foram compreendidos por meio da análise de conteúdo temático-categorial, destacando-se os aspectos qualitativos das respostas. Os garotos, por exemplo, foram quase unânimes ao indicar a prática do ficar como uma opção declarada para as experiências afetivas e amorosas. As respostas nos questionários podem ser resumidas em algumas frases como: - Nunca namorei sério; - Foram apenas beijinhos; - Eu só gosto de ficar; - Às vezes, eu agarro, sem relacionamento sério; Nunca namorei mais que dois meses.

A diferença nos discursos está no fato de que os adolescentes mais novos, entre 12 e 15 anos, referem-se a relacionamentos mais voltados para beijos, carícias ou amassos como condutas típicas do ficar. Entre os adolescentes de 16 e 17 anos, o ficar ganha a conotação e a possibilidade de sexo, e a expressão passa a ser substituída pelo pegar. Muitos adolescentes também resolveram atribuir conceitos ou qualificar a vida afetiva, como: muito boa, muito amorosa, superdez.

Em relação aos relatos das meninas sobre a vida afetiva ou amorosa, uma parte delas demonstra pudor e preocupação em não se tornarem "apenas" uma garota "de ficar" aos olhos dos meninos. Preocupam-se também em poder relatar as experiências amorosas decorrentes de relacionamentos mais sérios e duradouros. Conquistar o status de namorada e um dia casar revelou-se como o sonho presente em vários relatos dentre as garotas pesquisadas, inclusive algumas bastante jovens. Três delas, de 14, 16 e 17 anos, usaram a expressão "não sou de ficar", e afirmaram preferir relacionamentos compromissados. Outras afirmaram gostar de ficar, mas preferem ser a "namorada" em vez da "ficante". Gostam de serem percebidas como "uma menina para casar!". Uma adolescente, de 17 anos, ajuda a resumir essa ideia: - Diferente das relações que existem hoje em dia entre os jovens, me valorizo! 
As adolescentes deixaram patente preferir não serem vistas como meninas "que ficam". Discursam conforme o lugar que acreditam que uma mulher deva ocupar, e, embora não descartando a experiência do ficar, afirmam que esperam de suas relações afeto, carinho, respeito e atenção. É possível perceber, portanto, que, desde a adolescência, meninos e meninas não compartilham os mesmos planos, ou seja, que existe assimetria entre os gêneros, conforme defendido por Brandão (2004).

Para as adolescentes, o casamento é visto como um sonho, revestido de ideais e transformado, em muitos casos, na esperança ou na possibilidade de uma vida melhor, pois refere-se a um comportamento aceito e esperado pela sociedade, que denota compromisso firmado aos olhos humanos e aos olhos das igrejas. Exemplo disso foi colhido na manifestação de uma menina de 13 anos, que revelou o sonho de se casar na igreja, e acrescentou que, até isso acontecer, pretende "apenas estudar", refutando a possibilidade de ficar com alguém: - Quero casar na igreja de véu e grinalda!

Outras meninas também acentuaram uma visão romântica do amor e do casamento, afirmando esperar o príncipe encantado que garanta "uma vida compartilhada a dois, no amor", como disse uma garota de 17 anos. Esperam também, com pragmatismo, que esse príncipe possa trazer melhores condições sociais para ela e para os filhos que venham ter, acrescentando que almejam uma vida diferente das irmãs e das amigas mais velhas.

Ainda sobre as meninas que afirmaram ficar, muitas delas acrescentaram não deixar de manter a esperança de convencer o garoto a efetivar o namoro e, assim, estabelecerem um relacionamento com vínculo, sustentado no plano de noivado e do casamento. Nesse sentido, uma garota de 16 anos revelou gostar de relacionamentos sérios, mas salientou que, quando se apaixona por um garoto e ele quer apenas ficar, decide, então, "ir curtindo, até que o namoro aconteça". Tal atitude pode ser associada ao ditado popular que diz: "mulheres transam para namorar, enquanto os homens namoram para transar".

O comportamento das meninas em busca de relações mais duradouras leva a outros matizes do relacionamento entre os gêneros. Cabe registrar os depoimentos sobre casos de meninas que engravidam intencionalmente, pois as manifestações mais frequentes eram no sentido de que a maioria das meninas que se submete a essa situação faria isso para "segurar o namorado". Uma menina de 16 anos disse: - Muitas garotas só faltam morrer pelos seus namorados. Outras duas adolescentes, uma de 16 e outra de 17 anos, afirmaram que muitas engravidam porque acham que isso as torna "especiais" e que, assim, receberiam parte do afeto que uma criança recebe.

Dentro do contexto de vulnerabilidade social, situação em que se encontram muitas das adolescentes das comunidades onde a pesquisa foi realizada, a gravidez pode ser compreendida também como uma forma de regressão, uma tentativa de voltar a ser criança e de receber os afetos perdidos. Pela maternidade, receberão a dedicação e a atenção do parceiro ou das pessoas próximas, sanando suas carências afetivas, como se ela trouxesse benefícios secundários.

Sobre as repercussões da gravidez em adolescentes, Farias (2010) caracteriza o perfil de adolescentes cuja concepção ocorreu no período de 10 a 14 anos em contexto de vulnerabilidade social. As adolescentes tinham conhecimento e acesso a métodos contraceptivos antes da gravidez, que ocorreu a partir do seu desejo. Nesse mesmo trabalho, 
menciona que, entre as reações iniciais dos pais, ou dos responsáveis, havia raiva, susto e culpa por não terem conseguido evitar que elas tivessem engravidado tão cedo.

\section{Experiências sensuais/sexuais: eles citam, elas descrevem}

Os adolescentes foram também questionados sobre as experiências de contato corporal (beijos, abraços, etc.) que tiveram, e a idade em que ocorreram pela primeira vez. Em relação às experiências mais diretamente relacionadas ao sexo - ou de conteúdo erotizado - apareceram com mais ênfase nos textos dos adolescentes masculinos, inclusive com um relato de participação em sexo grupal.

Em outras menções, listavam as experiências nesse campo de forma gradativa quanto à intensidade/intimidade, começando por selinhos (beijos sem o uso da língua) até a descrição de terem feito sexo oral ou anal, algumas vezes relacionados a uma forma de evitar a gravidez. Os rapazes afirmaram ter tido as primeiras experiências de contato como beijos e "amassos", conforme suas próprias palavras, entre 11 e 12 anos. Entretanto, alguns deles não fizeram menção à idade.

Entre as garotas pesquisadas, os relatos tiveram algumas variações em relação aos dos garotos. A primeira diferença de maior destaque observada foi na forma do conteúdo dos enunciados discursivos, pois, enquanto eles citam as experiências vividas, elas buscam descrevê-las e justificar suas escolhas, como, por exemplo, o fato de ainda não terem beijado ou feito sexo. Muitas garotas admitiram a virgindade e justificaram não responder algumas questões por não terem tido experiências sexuais, e evitavam dar qualquer indício de contatos mais íntimos, demonstrando preocupação com respostas que mencionassem sexo: -
Nunca beijei, só abracei, mas nada demais, disse uma de 15 anos. Outra, de 17, afirmou o seguinte: - Só havia beijos e nada, além disso. Ainda sou virgem, graças a Deus!

Um grupo de garotas, contudo, expôs com clareza suas experiências sexuais, apresentando idade e detalhes do ocorrido. Não demonstraram incômodo ao descrever as vivências, dentre as quais apareceram relatos de meninas que fizeram sexo pela primeira vez aos 12 anos e até antes. Eis o relato de uma delas:- Perdi minha virgindade com 10 anos, e não me arrependo. Tenho relações com meu namorado, e, hoje em dia, quem não tem?

Diante das unidades de registros apreendidas nas respostas dos participantes, destacou-se a marcante diferença nas percepções e nos discursos sobre o tema sexualidade humana entre os adolescentes e as adolescentes, corroborando dados de outros trabalhos, como Brandão (2004) e Borges (2004). Em outras palavras, podemos dizer que, mesmo em tempos modernos e sendo as pessoas pesquisadas jovens, parece persistir nas meninas o discurso romântico em torno dos encontros e desencontros entre os sexos, enquanto os meninos relatam relacionamentos sem menção de compromisso.

\section{Considerações finais}

As primeiras experiências sexuais são datadas em seus relatos em períodos precoces do desenvolvimento, mormente no início da puberdade, por volta dos 12 anos, tanto meninos, quanto meninas. Ressalta-se a diferença do conteúdo discursivo entre os gêneros a respeito de tal temática, tanto no que se refere à maneira como buscam informações e como avaliam as consequências de um ato sexual como também a respeito do que esperam de uma relação amorosa. Entre os garotos, destoa 
o desejo manifesto de experimentar um contato afetivo-sexual pelo efeito que o ato, em si, pode proporcionar - como prazer ou aceitação social - enquanto as garotas mencionaram esperar, mesmo de um encontro furtivo, algum comprometimento.

Foi verificado que conhecem os métodos anticoncepcionais e de prevenção às DST, acreditando que adotam os cuidados necessários para se protegerem dos riscos inerentes a um ato sexual. Mencionam a pílula e a camisinha como os principais meios de contracepção e de prevenção às doenças venéreas, e revelam saber onde buscar informação e orientação sobre essas questões. Entretanto, aparecem relatos de opção pelo coito interrompido e pelo uso da pílula do dia seguinte, ou ainda, de prática sexual sem a preocupação de qualquer cuidado profilático, assertivo ou não.

Valorizaram o papel da família, principalmente o do pai e o da mãe, como fonte segura de informação, inclusive afirmam preferir ser orientados por pessoas mais velhas, com experiência no assunto, mas não mencionaram o papel de professores e o da escola nesse processo. Destacam também que recorrem a drogarias para conseguir métodos contraceptivos, lugares onde raramente possam ser orientados, pois tratase de estabelecimentos comerciais, em que o atendimento é feito por balconistas nem sempre preparados, algo hipoteticamente diferente do que poderia ocorrer em uma UBS ou em uma escola.

Este trabalho reforça as opiniões de vários segmentos da organização civil de que é preciso promover e integrar melhor as ações dos sistemas públicos de educação e de saúde no trabalho com adolescentes, capacitando educadores e profissionais de saúde para promoverem efetivamente o desenvolvimento pessoal e social da população e, dessa forma, possibilitar a eles a vivência da sexualidade de modo seguro desde as primeiras experiências, com a adoção de comportamentos de prevenção e de cuidados - consigo e com o outro.

Conclui-se que, mesmo em tempos de AIDS e de um discurso social de incentivo ao exercício sexual, os jovens pesquisados estão vulneráveis, pois, embora tenham as informações necessárias para se protegerem, não incorporaram os usos e os costumes sexuais considerados seguros. Verificou-se que os adolescentes, mesmo conhecendo os métodos anticoncepcionais e de prevenção às DST e afirmando que não se expõem a riscos, declaram que os amigos não fazem isso. Relacionando tais informações com os dados que apontam o alto índice de partos entre adolescentes em Porto Velho, que superam $25 \%$ dos registros, podemos perceber as consequências de uma falha nas políticas de atenção aos jovens. 


\section{José Juliano Cedaro}

Doutor em Psicologia. Professor em Psicologia da Universidade Federal de Rondônia, Rondônia - RO - Brasil.

Email: cedaro@msn.com

\section{Luana Michele da Silva Vilas Boas}

Mestre em Psicologia, atendimentos psicoterapêuticos, Rondônia - RO - Brasil.

E-mail: luanavilasboas3@hotmail.com

\section{Renata Moreno Martins}

Especialista em Saúde da Família pela Universidade Federal de Rondônia, Rondônia - RO - Brasil.

E-mail: renata_moreno@hotmail.com

\section{Endereço para envio de correspondência:}

Universidade Federal de Rondônia- Departamento de Psicologia

BR 364, KM 9,5 - Porto Velho - RO - Brasil. CEP: 76900-900

Recebido 1/7/2010, 1a Reformulação 25/11/2011, Aprovado 10/1/2012.

Altmann, H. (2009). Educação sexual em uma escola: da reprodução à prevenção. Cadernos de pesquisa: revista de estudos e pesquisa em educação, 39(136), 175-200.

Atkins, D. Best, D. \& Shapiro, E. N. (2001). The third U.S. preventive services task force: Background, methods and first recommendations. American Journal Prevention Medical, 20(3, Supl,1),1-108

Bardin, L. (2002). Análise de conteúdo. Lisboa: Edições 70.

Borges, A. L. V. (2004). Adolescência e vida sexual: análise do início da vida sexual de adolescentes residentes na zona leste do município de São Paulo. Tese de doutorado, Faculdade de Saúde Pública, Universidade de São Paulo, SP.

Brandão, E. R. (2004). Iniciação sexual e afetiva: exercício da autonomia juvenil. Tese de Doutorado, Universidade Estadual do Rio de Janeiro, RJ.

Brasil. (1999). Ministério da Saúde. CEBRAP - Centro Brasileiro de Análise e Planejamento. Pesquisa sobre comportamento sexual e percepções da população brasileira sobre HIV/AIDS. Brasília, DF: Ministério da saúde - PN/DST/AIDS.

Brasil. (2009). Ministério da Saúde. DATASUS. Coordenação Nacional de DST/AIDS. Recuperado em 15 agosto, 2009 de http://tabnet.datasus.gov.br/cgi/tabcgi.exe?idb2007/d0201. http:
def.

Brasil. (2010). Ministério da Saúde. Boletim Epidemiológico DST/AIDS, ano VII, no I. Brasília, DF. Recuperado em 06 outubro, 2011 http://www.aids.gov.br/publicacao/boletimepidemiologico-2010.

Brasil. (2011). Ministério da Saúde. DATASUS. SIAB (Sistema de Informação da Atenção Básica). Brasília, Recuperado em 26 outubro, 2011, http://tabnet.datasus.gov.br/cgi/siab/ siabsdescr.htm.

Farias, R. (2010). Gravidez entre 12 e 14 anos: repercussões na vida de adolescentes em contexto de vulnerabilidade social. Dissertação de mestrado, Universidade Federal de Santa Catarina, Centro de Filosofia e Ciências Humanas, Florianópolis, SC.

Flick, U. (2009). Introdução à pesquisa qualitativa. Porto Alegre: ARTMED.

Gubert, D., \& Madureira, V. S. F. (2008). Iniciação sexual de homens adolescentes. Ciência \& Saúde Coletiva, 13(Supl. 2), 2247-2256.

Justo, J. S. (2005). O «ficar» na adolescência e paradigmas de relacionamento amoroso da contemporaneidade. Revista do Departamento de Psicologia, 17(1), 61-77.

Meincke, S. M. K. (2007). A construção da paternidade na família do pai adolescente: contribuição para o cuidado de enfermagem. Tese de doutorado, Universidade Federal de Santa Catarina, Centro de Ciências da Saúde, Florianópolis, SC.
Moreira, M. \& Juarez, F. (2004). Comportamento sexual de adolescentes do sexo masculino de baixa renda: a comunidade de Chão de Estrelas, em Recife, Pernambuco. In Anais do XIV Encontro Nacional de Estudos Populacionais, ABEP, Caxambu, MG.

Poeschl, G. (2003). Representações das diferenças entre os sexos, práticas familiares e relações entre homens e mulheres. Estudos: revista da Universidade Católica de Goiás, 30(1), 31-49.

Porto Velho. (2008). Produção de marcadores de avaliação. Secretaria Municipal de Saúde. Divisão de Saúde. Prefeitura de Porto Velho, RO.

Richardson, R. J. (1999). Pesquisa social: métodos e técnicas (3a ed.). São Paulo: Atlas.

Silva, J. B. S. (2004). Encontros e desencontros na trajetória percorrida pelos adolescentes a partir da gravidez. Dissertação de mestrado, Universidade Federal de Santa Catarina, Centro de Ciências da Saúde, Florianópolis, SC.

Spindola, T., \& Silva, L. F. F. (2009). Perfil epidemiológico de adolescentes atendidas no pré-natal de um hospital universitário. Escola Anna Nery: Revista de Enfermagem, 13(1), 99-107.

Taquette, S. R., Vilhena, M. M., \& Paula, M. C. de. (2004). Doenças sexualmente transmissíveis na adolescência: estudo de fatores de risco. Rev. Soc. Bras. Med. Trop., 37(3), 210-214.

Turato, E. R. (2005). Métodos qualitativos e quantitativos na área da saúde: definições, diferenças e seus objetos de pesquisa. Revista Saúde Pública, 39(3), 507-514.

Velho, M T A C \& Souza, M L (2003). Cestação na adolescência: um marco na construcão de vida do ser-mulher Tese de doutorado, Universidade Federal de Santa Catarina, Centro de Ciências da Saúde, Florianópolis, SC.

Villela, W., \& Doreto, D. T. (2006). Sobre a experiência sexual dos jovens. Cadernos de Saúde Pública, 22(11), 2467-2472. 